\title{
ANALYZING AGAMEMNON: CONVERSATION ANALYSIS AND PARTICLES IN GREEK TRAGIC DIALOGUE
}

\author{
Evert van Emde Boas
}

\section{Introduction}

The aim of is this paper is to demonstrate the utility of Conversation Analysis (CA), a strand of sociolinguistics, for the appreciation of ancient Greek dialogue texts, with a particular view to the use of Greek particles. Since CA appears to be largely unknown within classics, ${ }^{1}$ I will begin by providing a basic outline of its principles and methods. The heart of my discussion, however, is formed by a contrastive analysis of two dialogue scenes from Greek tragedy - Aeschylus, Agamemnon 931-44, and Sophocles, Ajax 1346-73 — both featuring a recalcitrant Agamemnon as the object of a delicate piece of persuasion. I hope to show that an analysis along the lines proposed below may shed new light not only on the workings of several Greek particles whose

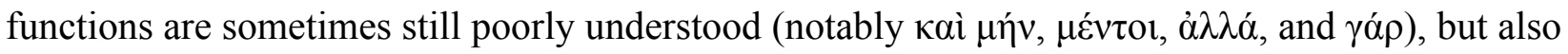
on the dynamics of Greek tragic dialogue more generally.

\section{Conversation Analysis: methods and terminology}

CA was pioneered in the late 1960s by a group of sociologists, led by Harvey Sacks until his early death in a car crash. ${ }^{2}$ The method is, at heart, inductive: CA began with the analysis of hundreds of hours of taped, naturally occurring conversations in American English, with the aim of distilling from this material observable patterns and mechanisms regulating conversation as a social phenomenon. In the decades after its conception, CA has become a methodology of 
importance not only in sociology, but also in (socio)linguistics, psychology, communication studies, education studies, and so on. It has also broadened its scope in terms of the languages studied: especially in the last two decades, a great deal of work has been done in CA on, for instance, German, Russian, Japanese, Mandarin Chinese, and modern Greek. ${ }^{3}$

This bare-bones history raises methodological issues for classicists: can a methodology that was specifically designed for the study of naturally occurring conversation in living languages ever be usefully applied to the study of a highly stylized form (such as tragic dialogue) in a dead language (such as ancient Greek)? Two points may be made here: first, CA appears to have uncovered some fundamental and, apparently, universal aspects of human conversation, and the evidence furnished by Greek literature provides every reason (as we shall see) to assume that such mechanics were operative in fifth-century Greece as much as anywhere. Second, as to the question of stylization, I would argue that for tragic dialogue to be intelligible for audiences (and readers), it had to make use of those same fundamental mechanisms, even if in a distinct (or, perhaps better, a "concentrated") form. ${ }^{4}$

A last methodological point, which might be raised by those familiar with recent research on Greek particles, is why one would turn to Conversation Analysis rather than its similar-looking (but only distantly related) cousin Discourse Analysis (DA). ${ }^{5}$ In some form or other, after all, DA is wholly responsible for the breakthroughs in Greek particle research achieved in recent decades, spurred on in particular by the work (on Latin discourse particles) of Caroline Kroon. ${ }^{6}$ Yet there are ways, I think, in which CA can help us where DA cannot. One reason for this is CA's specific focus on conversation, where DA typically offers a more unifying model of discourse, including monological texts. Another benefit of CA is the fact that it is particularly interested (as we shall again see) in those moments where conversation runs off the tracks - through mishearings, 
misunderstandings, and so forth. Here too, CA may offer handles on tragic dialogue that DA (which principally describes "well-formed" discourses) perhaps cannot.

Let us turn to the details of the model. The topic within CA that will be most relevant for my discussion is that of "sequence organization."7 The term "sequence," here, refers to the fact that conversational turns performing certain actions are typically followed by turns performing certain other actions: greetings are followed by greetings, questions are followed by answers, requests by acceptances or refusals, and so on. In CA, such paired sets of speaking turns - so-called "adjacency pairs" - constitute the most basic organizational resource of conversation, used in most forms of talk-in-interaction. When one speaker has uttered the first part of such a pair - the "first pair part" (FPP) — not only is there a very strong expectation that s/he will stop speaking and that the floor will pass to her/his interlocutor, there is also a very strong expectation that the other person will respond with a particular kind of verbal action: the FPP projects its own completion by a "second pair part" (SPP). Examples (1)-(4) below show some straightforward adjacency pairs: ${ }^{8}$

(1) A: What time is it?

B: Eight.

(2) A: Would you like to have dinner with us?

B: Yeah, great.

(3) A: What time is it?

B: Oh, I'm sorry, I don't have a watch.

(4) A: Would you like to have dinner with us?

B: Well, ehm, I'd love to, but I have too much work. SPP - DECLINING (dispreferred)
FPP - QUESTION

SPP - ANSWER

FPP - INVITATION

SPP - ACCEPTANCE

FPP - QUESTION

SPP - NON-ANSWER (dispreferred)

FPP - INVITATION 
Examples (3) and (4) are also good examples of the phenomenon of "preference." This refers to the fact that the alternative types of SPP that can complement a certain type of FPP are not equivalent, or equally valued. "Dispreferred" SPPs, which in some way hinder the accomplishment of the activity projected by the FPP, are generally more elaborate than "preferred" responses. They typically involve hedges, delays, markers such as "ehm," accounts ("I have too much work"), and so forth. Figure 1 sets out some basic types of adjacency pair, with their preferred and dispreferred responses:

\begin{tabular}{|l|ll|}
\hline First Pair Part & $\begin{array}{l}\text { Second Pair Part } \\
\text { Preferred }\end{array}$ & \multicolumn{1}{|c|}{ Dispreferred } \\
\hline greeting/farewell & \multicolumn{2}{|c|}{ greeting/farewell } \\
\hline summons & \multicolumn{2}{|c|}{ answer } \\
request & acceptance & refusal \\
offer/invitation/proposal & acceptance & refusal \\
assessment & agreement & disagreement \\
question & expected answer & unexpected answer, non-answer \\
blame & denial & admission \\
\hline
\end{tabular}

Figure 1: Basic adjacency pairs

Preference, it should be stressed, is a structural phenomenon, having to do with social expectations $^{9}$ rather than individual psychologies — one may imagine rejecting an invitation to a party to which one really doesn't want to go. Multiple preferences may be operative at once: for instance, a self-deprecating assessment may elicit conflicting social expectations (agreement with the assessment, rejection of the self-deprecation). Speakers may also phrase their FPPs in a way 
which makes it easier to offer a dispreferred response, for instance the negative invitation "You can't come out to dinner with us, can you?," allowing an interlocutor to use the response which the FPP seems designed to elicit (“design-based" preference) — "No, that's right, sorry."

We now come to a crucial feature of sequence organization. The fact that CA speaks of adjacency pairs should not be taken to mean that the FPP and SPP necessarily are uttered consecutively. At any point in such a sequence, speakers can insert "expansions," to facilitate the most efficient possible resolution of the overarching sequence (the "base pair") and to prevent dispreferred turns. The basic idea is presented in Figure 2:

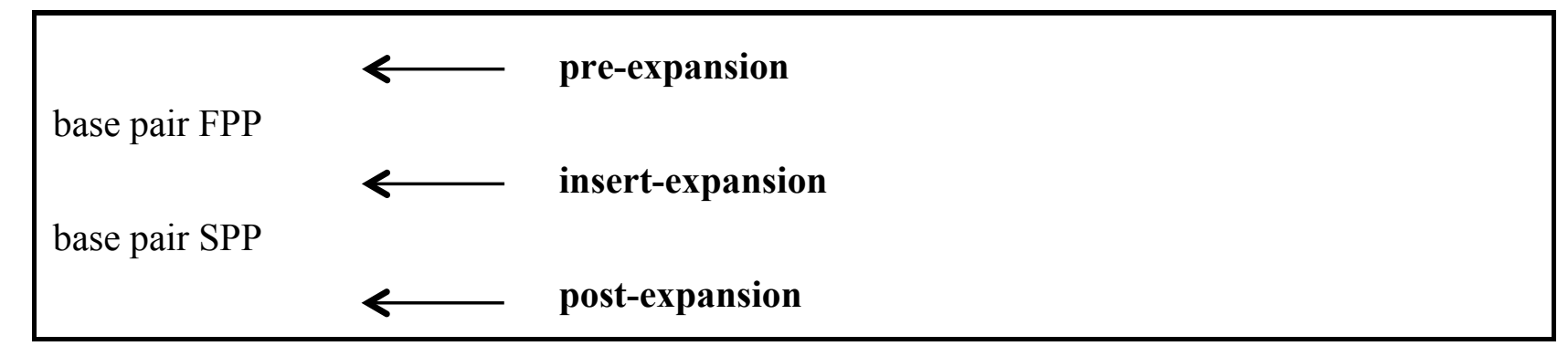

Figure 2: Expansions

Two examples of pre-expansions are (5) and (6):

(5) Pre-invitation:
A: Are you doing anything tonight?
QUESTION - FPP
B: No, why?
ANSWER - SPP
\} pre-expansion
A: Wanna come to dinner with us?
INVITATION - FPP
B: I'd love to.
ACCEPTANCE - SPP
\} base pair 
(6) Pre-telling:
A: Did you hear the news?
QUESTION - FPP
B: No, what?
ANSWER - SPP
\} pre-expansion

A: Jack won the lottery!

TELLING

base

"Pre-expansions" such as the pre-invitation in (5) or the pre-telling in (6) lay the groundwork for the production of the base pair, ensuring that the conditions are in place for an efficient resolution of the base pair and avoiding dispreferreds. The pre-invitation in (5), for instance, ensures that the invitation in the base pair will not be declined on the grounds of speaker B's being unavailable. The pre-telling in (6) ensures that news will actually be news.

"Insert-expansions" often function similarly. Before an SPP is produced, the second speaker treats one or more preliminary issues in order to permit a satisfactory resolution of the base pair. An example is the insert-expansion in (7):

(7) Insert-expansion (oriented to the SPP of the base pair):
A: Wanna come to dinner with us?
INVITATION- FPP
base pair
B: What time are you planning to go?
QUESTION - FPP
A: Eight.
ANSWER - SPP
\} insert-expansion
B: Great, I'd love to.
ACCEPTANCE - SPP
base pair

It may be observed that the expectations projected by the base pair's FPP remain fully relevant while an insert-expansion is being resolved - so much so, that the turns of the insert-expansion (for instance, the question-answer sequence in (7)) are automatically interpreted as significant for the completion of the base pair. 
Other insert-expansions function slightly differently, in that they are oriented towards resolving a misunderstanding or mishearing of the base pair's FPP. This process is called repair in CA: an example is (8):

(8) Insert-expansion (oriented to the FPP of the base pair); other-initiated self-repair:
A: Wanna come to dinner with us?
INVITATION- FPP
base pair
B: Sorry, come where?
QUESTION - FPP
A: To dinner. We're going out.
ANSWER - SPP
\} insert-expansion
B: Great, I'd love to.
ACCEPTANCE - SPP
base pair

"Post-expansions," finally, serve either to assess the SPP of the base pair and close the sequence, as in (9), or to reopen the base pair after a somehow unsatisfactory SPP has been produced. This can be for the purpose of repair, as in (10), or for other reasons, such as to reject, challenge, modify or disagree with the SPP, as in (11):

(9) Sequence-closing third (post-expansion):

A: Wanna come to dinner with us? INVITATION — FPP

B: I'd love to. $\quad$ ACCEPTANCE - SPP $\quad\}$ base pair
A: Okay, great.
ASSESSMENT - SCT \} post-expansion

(10) Post-expansion serving as repair:
A: Wanna come to dinner with us?
INVITATION- FPP
B: (inaudible)
SPP
\} base pair
A: Sorry, was that a yes?
QUESTION - FPP
B: Yeah, I'd love to.
ANSWER/ACCEPTANCE SPP \} post-expansion 
(11) Post-expansion challenging the SPP of the base pair:
A: Wanna come to dinner with us? INVITATION-FPP
B: Eh, I can't, too much work.
DECLINING - SPP
\} base pair

A: Sure you can, the work can wait! CHALLENGE - FPP

B: Well, all right, I'll come with you. ACCEPTANCE - SPP \} post-expansion

A final important point is that expansions themselves may be expanded, yielding complex sequences of, for instance, a base pair with a pre-expansion modified by a pre-expansion. An example of such a complex sequence is (12), where a request to borrow a book is preceded by a pre-request which topicalizes that book (making the base pair easier to resolve); the preexpansion is itself preceded by a "pre-pre," which facilitates the entire subsequent sequence:

(12) Complex sequence with a pre-pre:
A: Can I ask you for a favor?
QUESTION - FPP
B: Sure.
ANSWER - SPP \} pre-pre-expansion

A: Remember that book you mentioned? QUESTION — FPP

B: Yeah.

ANSWER - SPP \} pre-expansion

A: Could I borrow it tomorrow? REQUEST — FPP

B: Absolutely. $\quad$ AGREEMENT - SPP $\quad$ \} base pair

\section{Aeschylus, Agamemnon 931-44}

With this framework in mind, let us turn to two passages from Greek tragedy. The first of these, the stichomythia in the "tapestry scene" of Aeschylus' Agamemnon, has, of course, not suffered from a lack of critical attention. The scene plays a central role in the longstanding debate 
surrounding characterization in Greek tragedy, as well as various other debates on Aeschylean and Greek tragedy. ${ }^{10}$ In all this, it appears to me that the particles used in the scene, which contribute much to what Fraenkel called "Clytemnestra's dialectal fencing," ${ }^{11}$ have in fact not received the attention they deserve, and are often still insufficiently understood. Conversation Analysis can shed light here, not only in making sense of these elusive linguistic devices, but also in tracing the dynamics and nuances of the scene more generally. Printed below is the stichomythia, with my CA-style analysis of the sequencing of the dialogue (the various adjacency pairs are numbered for ease of reference - note that not all pairs are actually completed; different levels of indentation in the analysis represent different levels of embedding in the conversational structure; particles to be discussed are underlined): ${ }^{12}$

\section{Text and translation ${ }^{13}$}

905- Cl. Step on the purple cloths. 13

914- Ag. No. (That's for the gods.) 30

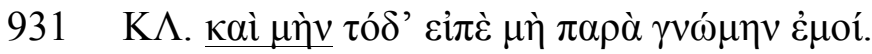

Now tell me this, without disguising your opinion-

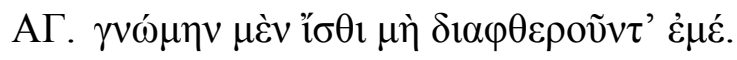

Be assured that I shall not be false to my opinion

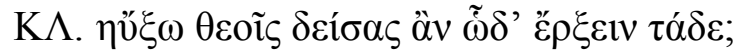

Might you have vowed to the gods, in a moment of danger, that you would do this thing?

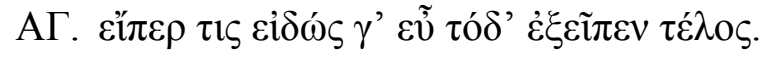

\section{Sequence}

1a FPP REQUEST (base pair)

1b SPP REJECTION (base pair) dispreferred

2a FPP REQUEST (preexpansion to 3: "prepre")

2b SPP AGREEMENT

3a FPP QUESTION (preexpansion to 5)

3b SPP ANSWER 
Yes, if somebody with proper knowledge had prescribed this ritual.

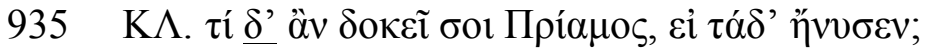

And what do you think Priam would have done, if he had a success like this?

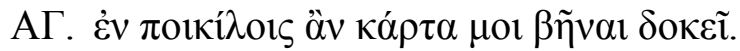

I definitely think he would have walked on embroideries.

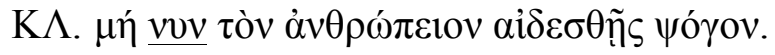
Then do not feel shame at the criticisms of mortals.

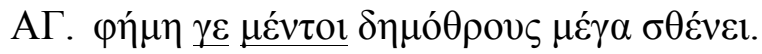
All the same, the buzz of popular talk is something very powerful.



But he who is not envied is not enviable.

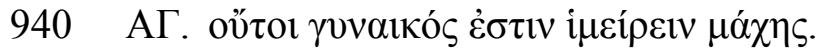

It is unwomanly, you know, to be eager for a fight.

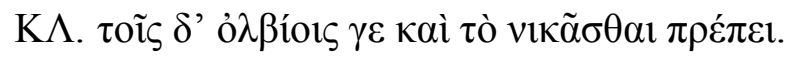

But for the fortunate, even a defeat can be honorable.

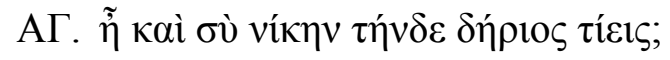

Do you really set such store by victory in this dispute?



Do as I ask! You are still the master, you know, if you yield to me of your own free will. 4a FPP QUESTION (preexpansion to 5)

\section{4b SPP ANSWER}

5a FPP REQUEST (postexpansion to $\mathbf{1}$ : challenge to $\mathbf{1 b})$

6a FPP ASSESSMENT (insertexpansion to $\mathbf{5}$; serves as a "pre-rejection")

6b SPP DISAGREEMENT

7a FPP ASSESSMENT/ADVICE (insert-expansion to $\mathbf{5}$; another "pre-rejection")

7b SPP DISAGREEMENT

8a FPP QUESTION (postexpansion to 7/insertexpansion to 5)

9a FPP REQUEST (sequence break $(\pi \mathrm{\imath} \theta \mathrm{ov})$, with account; reworking of $\mathbf{1 a} / \mathbf{5 a}$ ) 


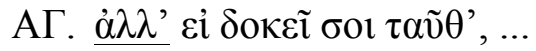
$\mathbf{1} \mathbf{b}^{\prime} / \mathbf{5 b} / \mathbf{9 b}$ sequence break $\left(\dot{\alpha} \lambda \lambda^{\prime}\right)$
Well, if that's what you want, ...
followed by SPP ACCEPTANCE

Clytemnestra, after a lengthy speech, has asked Agamemnon to descend from his chariot and step on the purple cloths (905-13); Agamemnon has refused (914-30). This, on my reading, is the base pair to which the entire stichomythia (931-44) forms a post-expansion. By means of an elaborately constructed piece of persuasion, Clytemnestra will get Agamemnon to revise his original rejection (his SPP).

Clytemnestra reopens the base pair with a carefully crafted series of moves. At 931, Clytemnestra's "introductory cast," "a masterly thrust," ${ }^{\text {, } 14}$ looks very much like the pre-preexpansion which we saw in (12) above: it is the "Can I ask you a question"-type of conversational turn, scaffolding the entire sequence to follow. Next, Clytemnestra proceeds to underpin her crucial turn of 937 by initiating two pre-expansions, at 933 and 935 . Although interpretation is difficult, it is clear that these two pairs are both designed to remove possible objections to a preferred SPP to Clytemnestra's suggestion, which is finally produced at 937 (they are therefore to be analyzed as on a level, rather than taking 933-34 as preparatory to 93536; this is also evident from the particle $\delta(\varepsilon)$ in 935 , discussed below). When 937, the gist of Clytemnestra's post-expansion, is at last uttered, Agamemnon does not give in straight away, but sputters, raising objections to 937 in a series of insert-expansions $(938-39,940-41)$. But when Agamemnon's third attempt (942), itself seemingly a post-expansion to the riposte provided by Clytemnestra at 941, threatens to steer matters too far off course, Clytemnestra abruptly cuts off the sequence, reasserting the relevance of her original request $(\pi i \theta 0 \tilde{v}, 943)$, after which Agamemnon yields (944). 
What do we gain from seeing Clytemnestra's turn at 931 as a pre-pre, her next turns as preexpansions, and the entire stichomythia as a post-expansion? For one, it may help us make sense of the contribution made by the particles used by the speakers, beginning with the combination

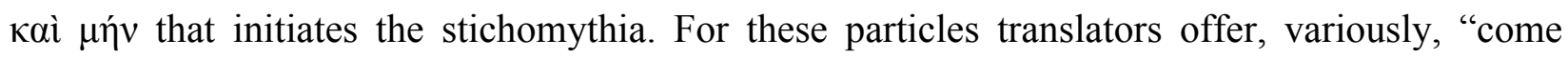
now" (Smyth), "well” (Sommerstein, Collard), "aye, ... and ... too" (Fraenkel), and so forth; most commentators ignore them. Fraenkel, who does treat the combination, follows Denniston's discussion in Greek Particles:

Denniston ... was correct in cataloguing it as an example of the 'progressive', not the adversative, use. ... 'Normally кaì $\mu \eta ́ v$ marks a new departure: it is mainly used after a strong stop'; this is the case here. ${ }^{15}$

But there are problems with Denniston's treatment: little clarity arises from it concerning the

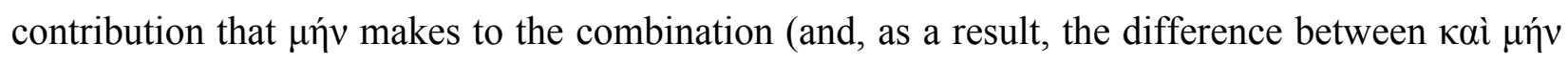
and other "progressive" particles or combinations); nor is it very clear how the progressive use of

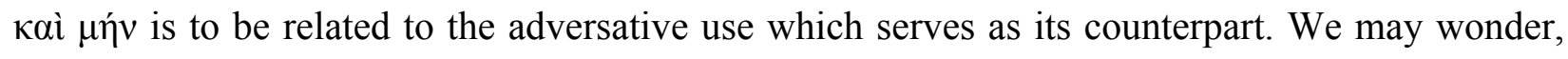
too, about the strength of the stop preceding this line.

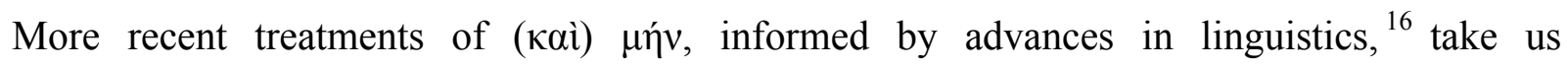

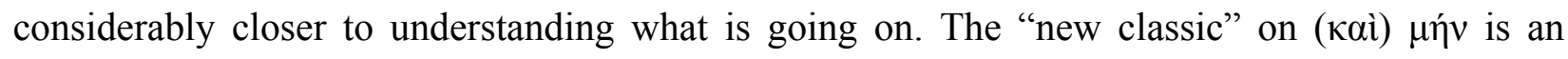
article by Gerry Wakker, ${ }^{17}$ who usefully incorporates notions of addressee expectation. Wakker argues that the central function of $\mu \eta \dot{v} v$ is to vouch for the truth of something in spite of what the addressee may think, and in fact often in anticipation of the addressee's disagreement or

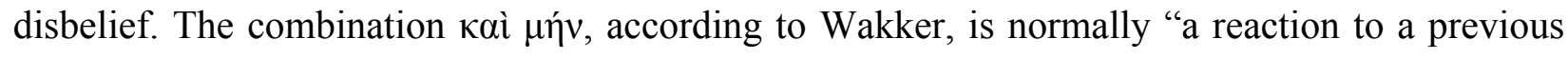

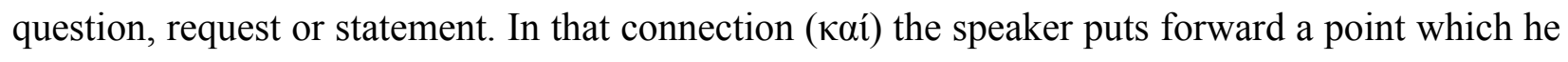


absolutely wants to stick to, a point of which he as it were personally guarantees the truth ( $\left.\mu \eta \eta^{\prime}\right) . " 18$ This is found particularly when "the speaker is actually contradicting the addressee or his supposed expectations or wishes." ${ }^{19}$ Yet cases such as the one under consideration present a

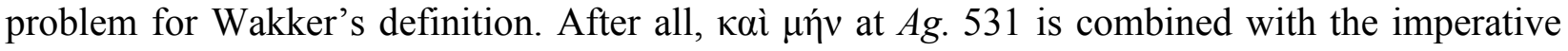
$\varepsilon i \pi \dot{\varepsilon}$, and it is hardly possible to "guarantee the truth" of a command or request. Wakker is well

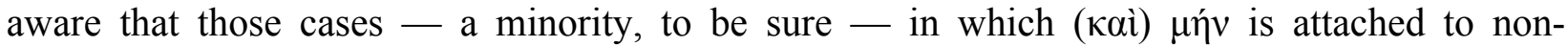
declarative utterances are problematic: in a footnote, she explains our present case as follows:

In my opinion, $\mu \eta v v$ is added to the imperative to intensify the order, in that it insists on its realisation. ... $\mu \eta v v$ is added to underline that the speaker truly wants the [order] to be executed, impossible or unexpected as this may seem. ${ }^{20}$

Yet insisting on the realization of the imperative seems like an unsatisfying reading in our case, too. As we have seen, the $\varepsilon i \pi \varepsilon$-line is only one initial step in a series, and intensification would appear out of place here.

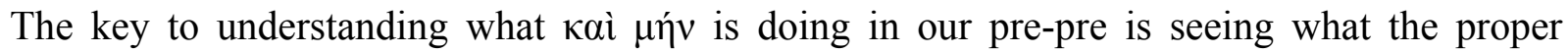
"scope" of the particle combination is ${ }^{21}$ and our CA-style analysis allows us to do this. My point may become clear from a simplified presentation of the structure of the stichomythia (the numbering is copied from the text analysis above): 


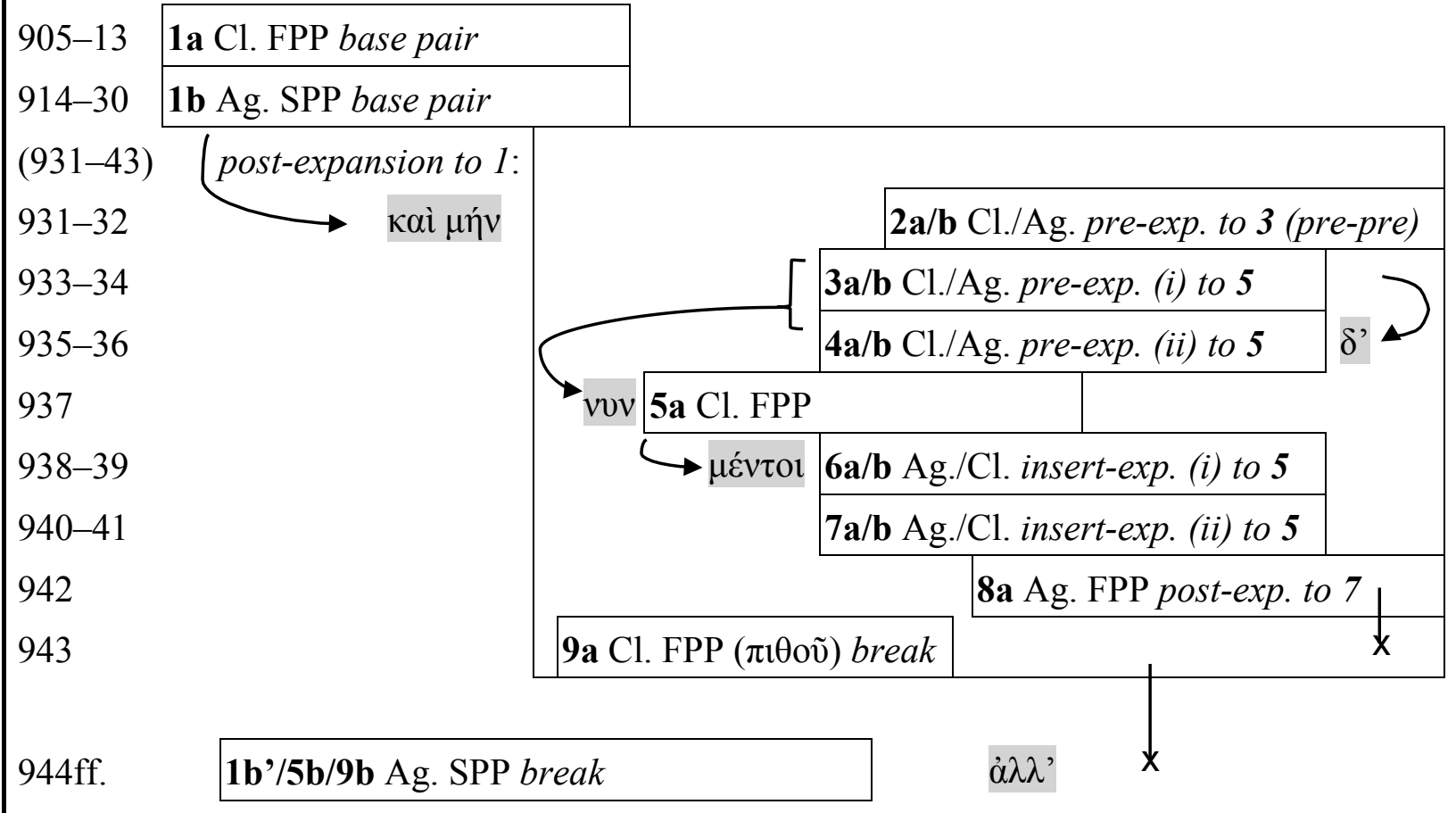

Figure 3: Schematic overview of Aesch. Ag. 905-944

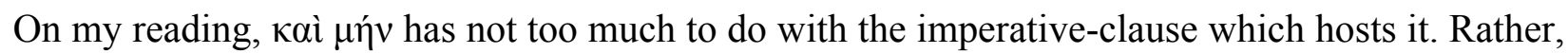
it is a signal modifying the entire conversational move that Clytemnestra is initiating, the whole of the post-expansion. It is at this point that notions such as "affirmation" and "counter-

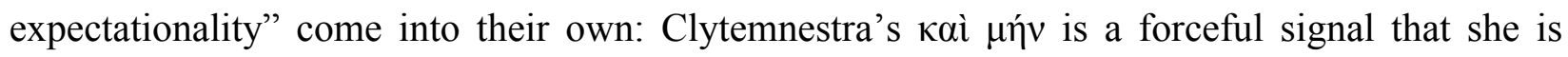
reopening/continuing the preceding sequence, regardless of Agamemnon's expectations (arising from the fact that he had, in what seemed a definitive move, closed the sequence initially by providing an answer to Clytemnestra's request).


be said about this" - is supported if we examine other cases in tragedy, falling both under 
Denniston's progressive and adversative headers. The combination is, it turns out, not infrequently found at the initiation of post-expansions. Here are two examples:

(13) Aesch. Ag. 1252-54, Cassandra and Chorus:

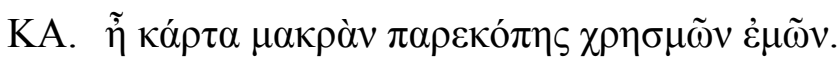

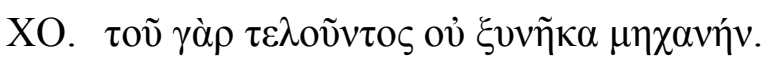

\} base pair

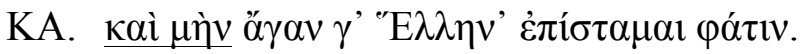

post-expansion

You have certainly strayed a long way from the track of my oracle! - Because I didn't understand what method he, the perpetrator, could use. - And yet I know the Greek language all too well. (Transl. Sommerstein)

(Cassandra challenges the Chorus' response to her complaint, particularly their "failure to

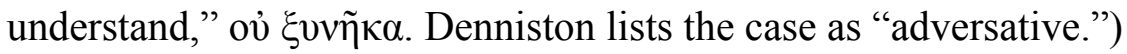

(14) Eur. Andr. 78-81, Andromache and Servant:

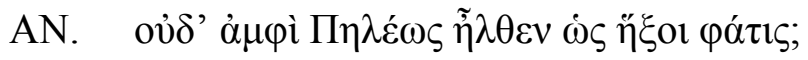

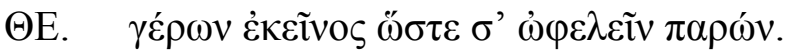

\} base pair

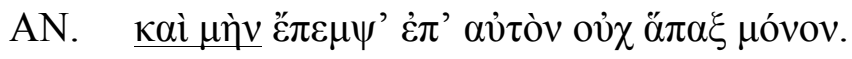

post-expansion

Is there also no word of Peleus' coming? - He is too old to help you even if he were here. - And yet I sent a message to him more than once. (Transl. Kovacs)

(Andromache is not satisfied with the Servant's answer.) $)^{22}$

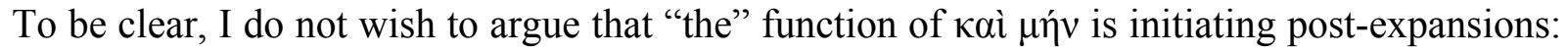

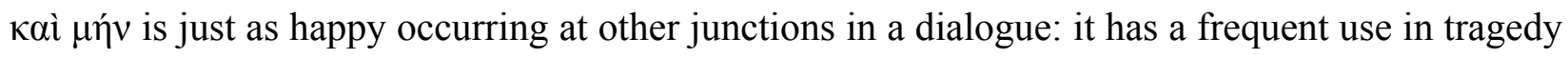


in marking entrances, ${ }^{23}$ and in turns which mark the fulfillment of a preceding request (SPPs, in CA-terms) ${ }^{24}$ Nor is it always found at the start of a speaker's turn. My point is that when we do find it at junctions similar to that in our Agamemnon-passage, the combination works to "color" the particular twist that the conversation is taking (as somehow contrasting with addressee beliefs or expectations); that aspect of кaì $\mu \eta ́ v$ may, I think, be generalized to other uses in other contexts: and it is precisely in carefully examining such different contexts that many advances in our description of Greek particles can still be made. ${ }^{25}$

Other particles, too, become more transparent on the basis of our CA-approach. At the transition from one pre-expansion to another (935), treating different topics, we find $\delta \varepsilon$, much as one would expect. ${ }^{26}$ As for vov (937) - a particle puzzlingly absent from Denniston's Greek Particles $^{27}$ - Fraenkel displays some hesitation:

Here, as often, vov has ... the ... meaning 'then', implying a quae cum ita sint. ... [I]t is not immediately clear what the 'then' points to. Presumably Clytemnestra draws her conclusion not only from the answer to her last question but also from the one before. ${ }^{28}$

My diagram above (fig. 3) offers support to Fraenkel's presumption: Clytemnestra's $\mu \grave{\eta}$... $\alpha i \delta \varepsilon \sigma \theta \tilde{n} \varsigma$ is set up by several preceding pairs of turns, and $v v v$ indicates that she is now coming to her point. ${ }^{29}$

Agamemnon's first objection at 938 is modified by $\mu \varepsilon ́ v \tau o$, a particle which is etymologically related to $\mu \eta v^{30},{ }^{30}$ and which shares with it notions of counter-expectationality. In an exemplary

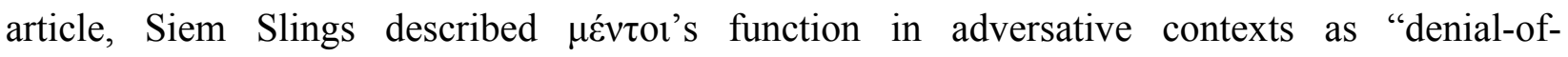

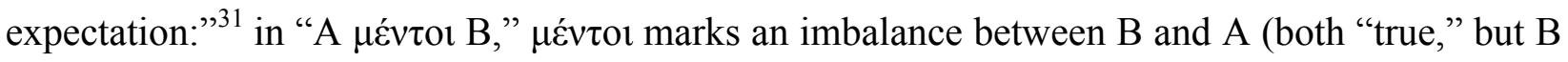
denies expectations/implications of A: for instance, "he is rich $\mu \varepsilon \dot{v} \tau o$ he is unhappy"). This value 
is very neatly demonstrated by the second instance of $\mu \varepsilon \dot{v} \tau 01$ in the stichomythia at 943 , where


present instance at 938 , the interpretative difficulty resides again in the fact that the imbalance marked by $\mu \varepsilon \dot{v} \tau \tau o$ is one that resides in the particular twists and turns of conversation (rather than one between propositions or "truths"). Given the build-up, in which Agamemnon has abetted Clytemnestra in removing obstacles to tapestry-walking, he might be expected to accede to his

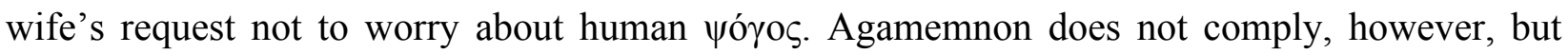
challenges the request in an insert-expansion: $\varphi \eta \mu \eta$ (for him the more relevant term, on which he concentrates with $\gamma \varepsilon$ ) is certainly something to be worried about. CA, incidentally, helps bring


suggests that a new (unexpected) point is being added to what precedes, and for that reason kai $\mu \eta ́ v$ would seem less at home in insert-expansions. ${ }^{32}$

Before we take stock of the stichomythia as a whole, one last particle deserves attention. $\dot{\alpha} \lambda \lambda$ ' in 944 is a classic example of what Denniston called the "assentient" use, in which the speaker consents to a request or affirmatively answers a question. Our case seems particularly relevant for his type (b):

(a) Agreement is presented as self-evident and inevitable. The speaker not only agrees, but repudiates the very idea that dissent is possible. ... (b) Agreement is presented, not as self-evident, but as wrung from the speaker malgré lui. $\dot{\alpha} \lambda \lambda \dot{\alpha}$ then points the contrast between the assent given and the considerations which have militated against the giving of it. In (a) 'Why', in (b) 'Well' is usually the best translation. ${ }^{33}$ 
Two more recent articles by Louis Basset and Annemieke Drummen have shown how this description may be brought in line with a more general function of $\alpha \lambda \lambda \alpha$ as a "correcting" or "replacing" particle: ${ }^{34}$ when it serves as a straightforward conjunction (particularly in oủ ... $\dot{\alpha} \lambda \lambda \dot{\alpha}), \dot{\alpha} \lambda \lambda \dot{\alpha}$ replaces explicit elements, but it may also, when functioning as a discourse particle, replace more implicit elements (such as implications of possible dissent) or even discourse topics. It is at this last level, I suggest, that Agamemnon's $\dot{\alpha} \lambda \lambda$ ' functions: it leaves behind the ongoing discussion about Agamemnon's objections (in CA-terms, his insert-expansions or the postexpansion as a whole), and replaces it with the execution of Clytemnestra's request (the SPP). As such, $\dot{\alpha} \lambda \lambda$ ' suggests that Agamemnon considers the debate in the stichomythia unresolved, but

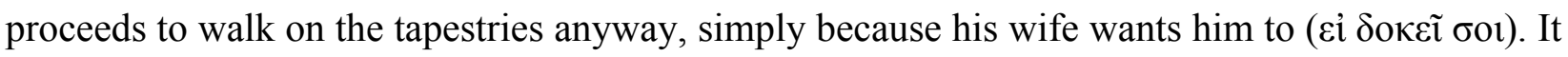
is a neat sign that Agamemnon consents to tapestry-walking even if he does not agree with it. ${ }^{35}$

Incidentally, if this reading of the function of the particle is on target, it militates against the “oriental despot" reading of Agamemnon's actions presented in the Denniston-Page commentary ("it is simply because he is at the mercy of his own vanity and arrogance, instantly ready to do this scandalous act"): ${ }^{36}$ a much more attractive reading, to my mind, is one which sees the stichomythia as "a plausible human portrayal of [the] process of being persuaded into an action about which one feels the severest misgivings." 37 We may note that Agamemnon's hesitation about the whole enterprise is emphasized again at 946-49.

A CA-style analysis, then, offers significant advantages in tracing the niceties of particle usage in individual contexts. It also allows us to identify some of the larger dynamics of character and power at work in the scene. Examining which speaker tends to initiate adjacency pair sequences, for instance, can reveal a great deal about who has the initiative in a conversation and the ability to steer it in a certain direction. In our stichomythia, this is clearly Clytemnestra (she initiates the 
driving sequences at 931, 933, 935, 937). When Agamemnon attempts to arrogate control of the conversation $(938,940,942)$ he is swiftly cut off and kept on track by his wife $(943)$. Related to this is the power to control the topic of conversation (incidentally, another major field of research in CA): here, too, we see that the battle is fought on Clytemnestra's turf: she is the one to bring forward crucial topics such as religious piety and popular censure at 933/935/937. Agamemnon tries another tack by making things personal at 940/942 — he presents the debate as a personal

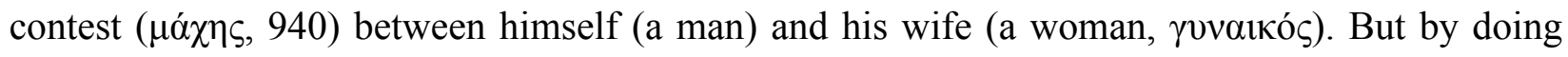
so, he seems to have already yielded on the larger issues, and in any case his attempt goes nowhere.

Clytemnestra, in short, comes to the stichomythia with a plan (witness the complex, layered build-up to her crucial turn in 937), and is able to control the direction it takes. In all this, it is worth keeping in mind the seemingly inferior position from which she is operating: not only as a woman trying to persuade a man (and a king), but also in having to reverse a decision which has already been made. In this respect, it is instructive to compare another passage from Greek tragedy featuring a very similar scene of persuasion, which is nevertheless different in a few vital aspects that CA can bring to light.

\section{Sophocles, Ajax 1346-73}

Although I have been unable to find the suggestion in print, I suspect that I am not the first to suppose that in composing the debate between Odysseus and Agamemnon in his Ajax, Sophocles may have had the tapestry scene from Agamemnon in mind. ${ }^{39}$ Apart from the similarity of content (Agamemnon being persuaded to do something he does not want to do), there is a striking verbal






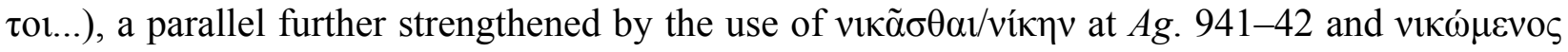
at $A j .1353 .{ }^{40}$ In this light, the repeated references to "trampling" ( $\pi \alpha \tau \varepsilon \tilde{v} v 1335, \pi \rho 0 \sigma \varepsilon \mu \beta \tilde{\eta} v \alpha l$ 1348) in the Ajax-passage may also not be coincidental. But even if we do not accept anything more than a superficial resemblance, a comparison of the conversational structure of the two passages may bring into focus some of the features particular to each of them. As above, I print the text with my analysis of the constituent adjacency pairs and expansion-sequences.

\section{Text and translation ${ }^{41}$}

1332- Od. Allow Ajax to be buried.

\section{5}

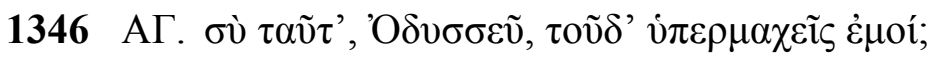

Odysseus, are you fighting for this man against me?

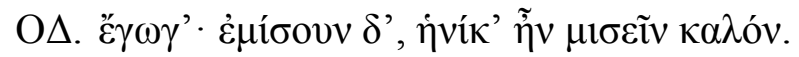

Yes! I hated him when it was honorable to hate him.

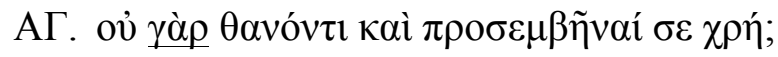

Now that he is dead, should you not trample on him?

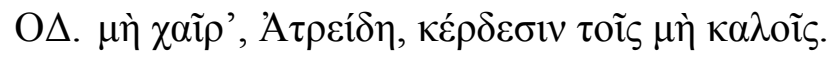

Son of Atreus, do not take pleasure in a superiority that is ignoble.

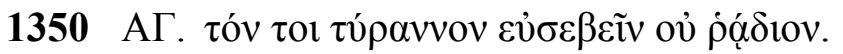

It is not easy for a ruler to avoid impiety

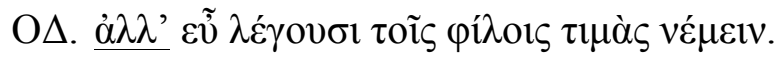

But he should honor his friends when they give good advice.

\section{Sequence}

1a FPP REQUEST (base pair)

2a FPP QUESTION

(insert-expansion to $\mathbf{1}$, oriented to $\mathbf{1 a}$ - initiation of repair of 1a) ${ }^{42}$

2b SPP ANSWER

3a FPP QUESTION

(post-expansion to 2)

4a FPP ASSESSMENT/ADVICE (counter to 3a; a dispreferred answer $\mathbf{3 b}$ is implied)

5a FPP ASSESSMENT

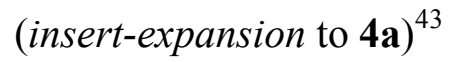

5b SPP DISAGREEMENT 


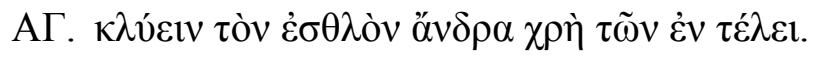

The noble man should obey those in authority

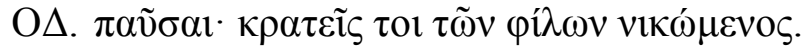

Enough! You win, when you give in to your friends.

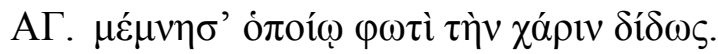

Remember what sort of man is the recipient of your kindness.

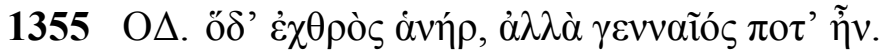

This man was an enemy, but he was noble.

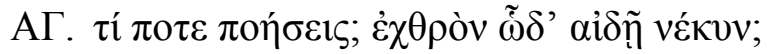

What is it you will do? Have you such respect for the corpse of an enemy?



His excellence weighs more with me than his enmity.

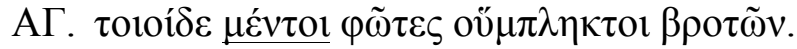
That is what inconsistent men are like.

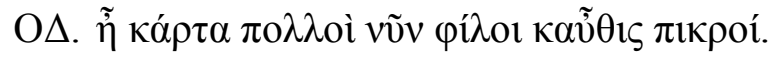
In truth many people are now friends and later enemies.

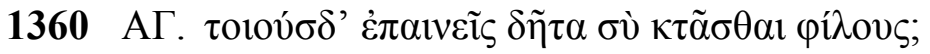
Do you approve of making friends of such people?

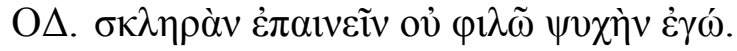

It is not my way to approve of a rigid mind.

\section{6a FPP}

ASSESSMENT/ADVICE ${ }^{44}$

7a FPP REQUEST (sequence break; reworking of $\mathbf{1 a}$, picking up $\mathbf{5 b}$ )

\section{8a FPP ASSESSMENT/ADVICE (insert-expansion to $\mathbf{1 / 7}$, oriented to $\mathbf{1 b} / \mathbf{7 b}$ )}

8b SPP ASSESSMENT 9a FPP QUESTION (post-expansion to 8; insertexpansion to $\mathbf{1 / 7}$, oriented to 1b/7b)

9b SPP ANSWER 10a FPP ASSESSMENT (post-expansion to 9)

10b SPP AGREEMENT 11a FPP QUESTION (post-expansion to 10)

11b SPP ANSWER 


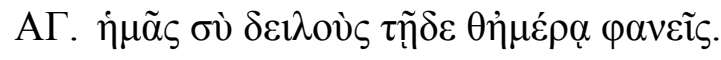

On this day you will make us seem cowards.

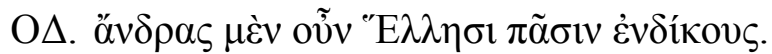

No, men who are just in the sight of all the Greeks.

АГ. öv

Then are you telling me to allow this body to be buried?

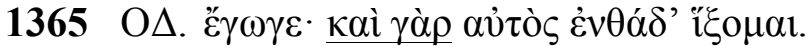

I am; why, I myself shall come this same pass!

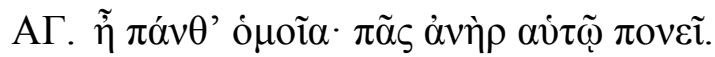

It is always the same! Every man works for himself.

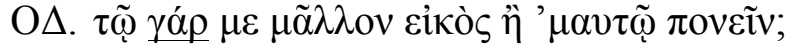

For whom am I likely to work if not for myself?

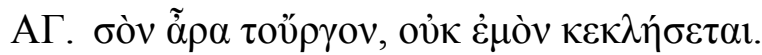

Then it shall be called your action not mine.

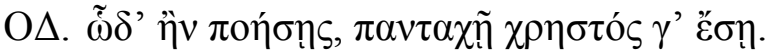

If you perform this action, in any case you will do well.



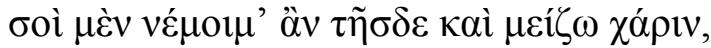

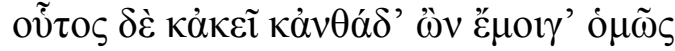

12a FPP

ASSESSMENT/

COMPLAINT

(post-expansion to

11)

12b SPP

DISAGREEMENT/

REJECTION

\section{3a FPP QUESTION}

(insert-expansion to $\mathbf{1}$, oriented to 1a - invitation for repair of

1a)

13b SPP ANSWER

\section{4a FPP}

ASSESSMENT/COMPLAINT

(post-expansion to 13)

14b SPP AGREEMENT/

ADMISSION

\section{5a FPP}

ASSESSMENT/WARNING

(insert-expansion to $\mathbf{1 / 7}$, oriented to $1 \mathbf{b} / 7 \mathbf{b}$ )

15b SPP AGREEMENT 1b/7b sequence break ( $\left.\dot{\alpha} \lambda \lambda^{\prime}\right)$, followed by SPP ACCEPTANCE (base pair) 




Indeed you can be sure of this, that to you I would accord a favor still greater than this one.

But he both here and there alike shall be a deadly enemy to me. But you may do as you wish.

Several points of contrast with our Agamemnon-passage immediately stand out. First, this stichomythia may be seen as a prolonged series of insert-expansions, rather than a post-expansion like in Agamemnon: while Clytemnestra has to reverse a rejection which Agamemnon has already entered into the record, Odysseus (who is, perhaps significantly, not a woman) sees his request not denied right away, but subjected to questioning and challenge. ${ }^{45}$ Related to this point is the different role that Agamemnon performs: whereas in the Agamemnon-stichomythia he was the reactive party, following Clytemnestra's lead, here he has the initiative throughout (he utters nearly all FPPs of the stichomythia), trying repeatedly to poke holes in Odysseus' case. To maintain the fencing metaphor: where Clytemnestra was thrusting, Odysseus is parrying. The result is a very different sense of the two characters' strategies of persuasion: Clytemnestra is dominant and aggressive, Odysseus is diplomatic and subtle. ${ }^{46}$

As part of this subtlety, we may note how Odysseus steers the conversation not so much by initiating sequences but by gently prodding Agamemnon into discussion of certain topics: the proper behavior of a ruler (1394-53), the qualities which may balance out $\varepsilon^{\prime} \chi \theta \rho \alpha(1355-59)$, the general unpredictability of life (1365-67). In this respect, Sabine Pfeiffer-Petersen has rightly

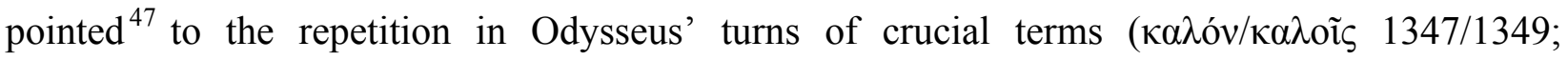



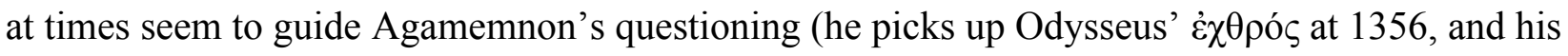
av̉ós at 1366). 
The particular twists and turns of conversation in the passage are, again, frequently marked by particle usage. The stichomythia is rich in turn-initial particles, ${ }^{48}$ and to discuss them all is well beyond the scope of this paper. I will focus in what remains on uses of $\gamma$ ó $\rho$, followed by briefer remarks on two particles already discussed above, $\dot{\alpha} \lambda \lambda \dot{\alpha}$ and $\mu \varepsilon \dot{\varepsilon} \tau \tau$.

Гó $\rho$ plays an interesting role in the cut and thrust of this dialogue. The particle has recently taken center stage in a stimulating discussion of Sophoclean stichomythia by Simon Goldhill, who notices the high frequency of $\gamma$ ó $\rho$ in the stichomythia at Antigone 730-57, and comments:

The particle gar ... is standardly translated "for," and marks the logical connection of the sentence with the preceding utterance. ... In stichomythia, where the previous sentence is the other speaker's, gar marks the picking up of an idea in agreement or disagreement ("no, because ...," "yes, because ..."). It is the node of distortion. It indicates the moment where the speaker takes up the assumption of the other and aggressively wraps it into his own world-view. Gar traces the transformation of reason into hostile disagreement. ${ }^{49}$


individual lines (offering a range of different translations for the particle), but he is all but clear on how ró $\rho$, in marking a "logical connection," can signify both "agreement" and "disagreement," or how it "takes up the assumption of the other."

The first thing to note is that "logical connection" is not the most helpful paraphrase of $\gamma$ óp's function: in fact, $\gamma \alpha \dot{\alpha} \rho$ can mark various kinds of discursive relationships between text segments, such as cause, explanation, justification, elaboration, and clarification - certainly not all of which have to do with logical relationships between clauses. The common feature of all such 
relations is that the text segment hosting $\gamma$ ó $\rho$ serves, in some way, a supporting role to another, more central, segment (very similar things could be said about English "for," incidentally) ${ }^{50}$

In conversation, this overall function of $\gamma$ ó $\rho$ takes on specific nuances depending on the point

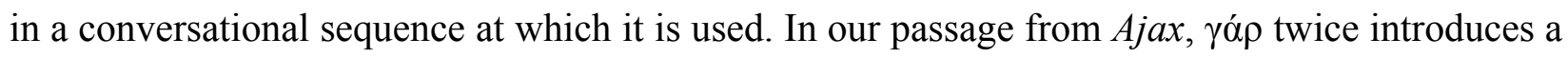
SPP $(1357,1367)$ : it is at such junctions that the translation "yes, for ..." can work. When the SPP with $\gamma$ ó $\rho$ complements an assertion in the FPP, the second speaker offers an explanation/justification for that assertion, implicitly verifying it. This is the case at 1366-67: "Every man works for himself." - "(Indeed, for) I am likely to work for myself above all others." (Note that Odysseus phrases this last reply as a rhetorical question.) ${ }^{51}$ Slightly more tricky is the use of $\gamma \alpha \dot{\alpha} \rho$ in replies to yes/no-questions: ${ }^{.2}$ in such cases, $\gamma \alpha \dot{\alpha} \rho$ implicitly offers the answer to the question by providing an explanation or justification, as at $1356-57 .:^{53}$ "Have you

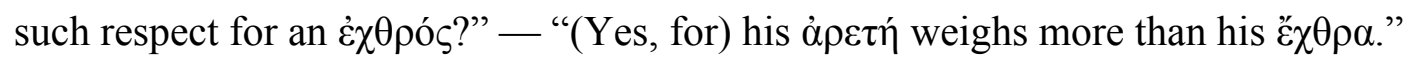

It should be noted that in this use of $\gamma \alpha \dot{\alpha} \rho$ in SPPs, the implicit answer it provides must conform to the design-preference of the FPP: in replies to assertions a $\gamma$ óp-clause implicitly provides the verification of that assertion, in answers to yes-no questions it implicitly provides the answer which the question is designed to elicit. It is only for this reason that $\gamma \alpha \dot{\alpha} \rho$ can also sometimes come to mean "no, for ...": when the initial assertion or question is directed towards "no," a SPP with $\gamma \alpha \dot{\alpha} \rho$ follows that direction. ${ }^{54}$ The idea that $\gamma \alpha \dot{\alpha} \rho$ can mark agreement or disagreement interchangeably thus needs considerable modification.

Odysseus' use of $\gamma \alpha \dot{\rho} \rho$ in the passage is emblematic of his role and strategy: confronted with Agamemnon's skeptical questions and complaints, Odysseus reasons with him by offering explanations and justifications: point by point, he defuses Agamemnon's objections and guides him in a different direction. ${ }^{55}$ Agamemnon's $\gamma \alpha \dot{\rho} \rho$ at 1348 , however, is of a very different kind, 
one for which Goldhill's "node of distortion" seems much more apt. The key difference is the

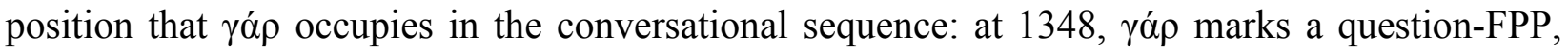
which opens an expansion-sequence: ${ }^{56}$ Agamemnon's question is a way of demanding further clarification to an answer which has not satisfied him (1347): it is at such points that $\gamma \alpha$ ó comes to mean "Are you saying that because ...?" (that is, "Am I to take that to mean that ...?"). ${ }^{57}$ The particular nuance that $\gamma \alpha$ ó expresses, and its "tone," thus depend on the place it occupies in a conversational sequence. It is certainly no coincidence that in our Ajax-passage we find Agamemnon using the particle in one way, and Odysseus using it in another. ${ }^{58}$

Lastly on $\gamma \alpha \dot{\alpha} \rho$, and by way of minor excursus, the basic point that the particle's sense depends on its place in a conversational sequence offers scope for a fine-tuning of Denniston's treatment of the particle. For instance, he classifies all the uses discussed above as "answer in the form of a question" 59 yet as we have seen, some are in fact much more "answer-like" than others. Moreover, the idea that $\gamma \alpha \dot{\alpha} \rho$ is often used in expansion-sequences allows us to make sense of a category which particularly troubled Denniston, his so-called "progressive" use of $\gamma \alpha \dot{\rho} \rho .{ }^{60}$ One of Denniston's examples, again taken from Ajax, must suffice here:

(15) Soph. Aj. 95-102, Athena and Ajax:

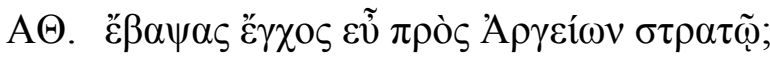

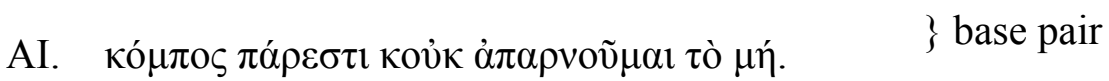

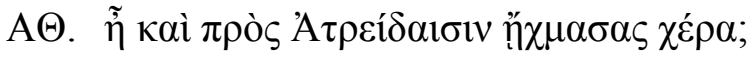



\} post-expansion 1 


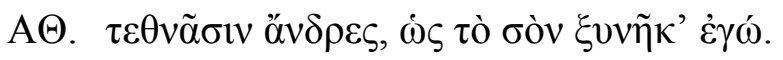

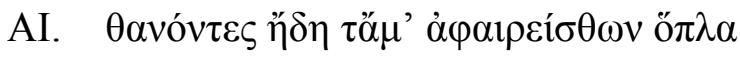

\} post-post (repair)

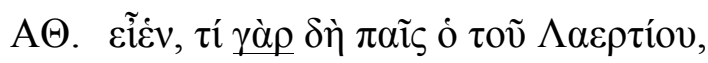
$\pi \mathrm{oṽ} \mathrm{\sigma o \imath} \mathrm{\tau ú \chi \eta \varsigma} \mathrm{\varepsilon ̌ \sigma \tau \eta \kappa \varepsilon v;} \mathrm{ì} \mathrm{\pi \varepsilon ́ \varphi \varepsilon v \gamma \varepsilon ́} \mathrm{\sigma \varepsilon ;}$

\} post-expansion 2

Have you well stained your sword in the blood of the Argive army? - I thank you; but tell me this, have you well stained your sword in the blood of the Argive army? — I have a right to boast, and I shall not deny it! — Did you arm your hand against the sons of Atreus too? - So that never again shall they refuse honor to Ajax. - The men are dead, if I understand your words. — Let them try to deprive me of my arms, now that they are dead! - So! But what of the son of Laertes, what is his situation? Did he escape you? (Transl. Lloyd-Jones)

Denniston finds it "puzzling" that $\gamma$ ó $\rho$ can be used when a speaker, "having been satisfied on one subject, wishes to learn something further." ${ }^{, 61}$ The puzzle is solved when we observe that $\gamma \alpha \dot{\alpha} \rho$, like we saw above, is used in post-expansions, when a speaker asks for further information to clarify a previous answer. At Ajax 101, this post-expansion happens to be one in a series, which leads Denniston to classify it as "progressive" (the transition is explicitly marked by $\varepsilon \dot{i \varepsilon v}$, which marks a "fresh point by a backward glance at what has been established"). ${ }^{62}$ That term, however, conceals the fact that $\gamma$ ó $\rho$ is still backward-looking: Athena is not simply moving on to a new point, but asking for a further point of clarification concerning Ajax's rampage: "Okay, so much

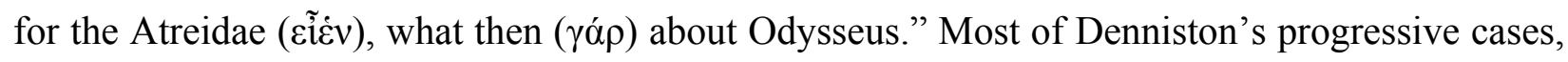
it turns out, can be explained in this way. 
Before I come to some concluding remarks, some brief comments on two other particles used by Agamemnon and Odysseus, $\dot{\alpha} \lambda \lambda \dot{\alpha}$ and $\mu \varepsilon \dot{v} \tau o$, will bear out the wider applicability of my earlier discussions. There is, for instance, another example of "assentient" $\dot{\alpha} \lambda \lambda \dot{\alpha}$ at 1370: Agamemnon breaks off the series of insertion sequences which he himself had initiated, and moves to give his permission. $\dot{\alpha} \lambda \lambda \dot{\alpha}$ again implies that Agamemnon consents without having changed his mind. ${ }^{63}$ The rest of Agamemnon's turn then serves as an elaborate hedge, and it is in this light that his use of $\mu \varepsilon ́ v \tau o r ~(1370)$ may also be seen. Given the repeated objections he has voiced earlier, the notion that he would defer to Odysseus in this (or any) matter may come, he suggests, as a surprise (hence the "denial-of-expectation"). For Agamemnon, this very deference is, of course, also a way to yield without giving up his position (he consents for Odysseus' sake,

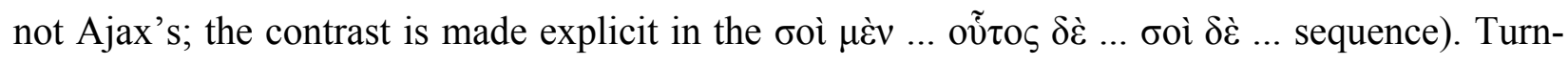
initial $\dot{\alpha} \lambda \lambda \dot{\alpha}$ is also found earlier in Odysseus' turn at 1351, which replaces Agamemnon's negative assessment (1350) with a positive one ${ }^{64}$ Finally, as for $\mu \varepsilon \dot{v} \tau o \imath$ at 1358: Denniston, widely followed by commentators, treats this instance of $\mu \varepsilon \dot{v} \tau o 1$, and many others in dialogue

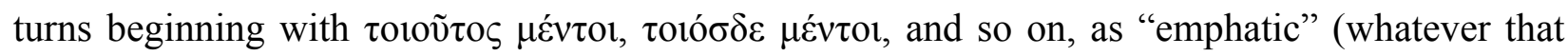
may mean), and as distinct from the particle's "adversative" or "progressive" senses. ${ }^{65}$ Yet I think the notion of denial-of-expectation is again present here, and would interpret the line as follows. Agamemnon implicitly concedes the point that Ajax had $\dot{\alpha} \rho \varepsilon \tau \eta$, but refuses to get on board (as he might have been expected to) with Odysseus' point that this $\dot{\alpha} \rho \varepsilon \tau \eta \dot{~ o v e r r i d e s ~ h i s ~} \check{\varepsilon} \chi \theta \rho \alpha$ (1357). Instead, Agamemnon claims that the shift in Ajax's demeanor proved him to be "unstable"

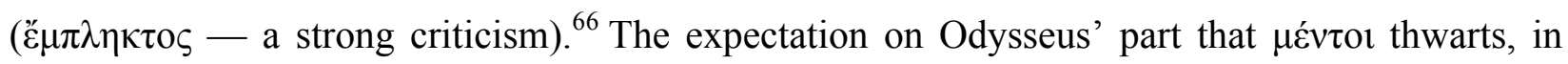
short, is that his view on the $\dot{\alpha} \rho \varepsilon \tau \eta \dot{-v s-\varepsilon ̈ \chi} \chi \rho \rho \alpha$ calculus might be taken as the last word: instead, Agamemnon relaunches the argument (a post-expansion). Again, the key to capturing the 
particle's nuances lies in tracing, not simply how it connects clauses or balances content, but how it marks particular twists in a conversation.

\section{Conclusion}

Recent years have witnessed a comeback of "formalist" approaches to Greek tragedy: ${ }^{67}$ after decades in which context was everything, it is, to my mind, a welcome development that language is once again taken seriously. Taking language seriously, however, ought to mean utilizing the full range of approaches with which we are furnished by modern linguistics. My discussions above are intended as a contribution to this end: Conversation Analysis offers ways of significantly improving our understanding of Greek literary dialogue - its fundamental mechanics, as well as the nuances and dynamics of individual scenes. It can help us in making sense of such frustratingly elusive devices as particles. My discussion has been intended to do no more than show the potential of such an approach: I have focused on argumentative scenes of persuasion, but many other kinds of conversation in Greek (and Latin) literature could be examined. ${ }^{68}$ In short, the scope for the application of this body of work to ancient literature is very large indeed.

Calleva Research Centre, Magdalen College, Oxford 


\section{Cited works}

Bakker, Egbert J. 1993. Boundaries, Topics and the Structure of Discourse: An Investigation of the Ancient Greek Particle $\delta \varepsilon ́$. StudLang 17.2: 275-311.

Bakker, Stéphanie J., and Gerry C. Wakker, eds. 2009. Discourse Cohesion in Ancient Greek. Leiden.

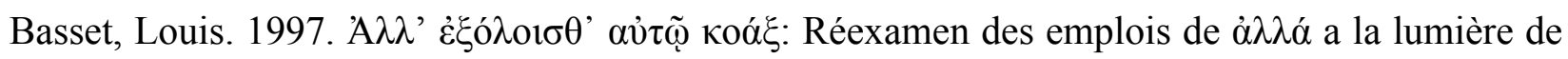
l'énonciation dans les Grenouilles d'Aristophane. In Rijksbaron 1997b, 75-99.

Beekes, Robert S. P. 2009. Etymological Dictionary of Greek, with the assistance of Lucien van Beek. Leiden.

Bonifazi, Anna, Mark de Kreij, and Annemieke Drummen. Forthcoming. Particles in Ancient Greek Discourse. Pragmatic Studies of Particle Use Across Genres. Washington, DC.

Burton, Deirdre. 1980. Dialogue and Discourse: A Sociolinguistic Approach to Modern Drama Dialogue and Naturally Occurring Conversation. London.

Culpeper, Jonathan. 2001. Language and Characterisation: People in Plays and Other Texts. Harlow.

Davidson, John. 2012. Aeschylus, Sophocles, Euripides. In A Companion to Sophocles, ed. Kirk Ormand, 38-52. Chichester.

Denniston, John D. 1954. The Greek Particles, $2^{\text {nd }}$ ed., ed. by K. J. Dover. London.

Denniston, John D., and Denys L. Page, eds. 1957. Aeschylus: Agamemnon. Oxford.

Dik, Helma. 2007. Word Order in Greek Tragic Dialogue. Oxford. 
Drummen, Annemieke. 2009. Discourse Cohesion in Dialogue: Turn-Initial $\alpha \lambda \lambda \dot{\alpha}$ in Greek Drama. In Bakker and Wakker 2009, 135-54.

Easterling, Patricia E. 1973. Presentation of Character in Aeschylus. G\&R 20.1: 3-19.

Emde Boas, Evert H. van. Forthcoming. Language and Character in Euripides' Electra. Oxford.

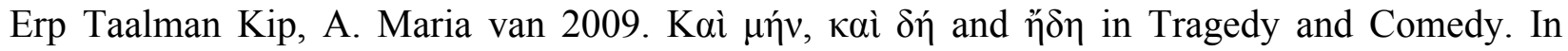
Bakker and Wakker 2009, 111-34.

Finglass, Patrick J. 2007. võv and vvv in Pindar. Mnemosyne 60.2: 269-73. , ed. 2011. Sophocles: Ajax. Cambridge.

Fraenkel, Eduard., ed. 1950. Aeschylus: Agamemnon. Oxford.

Garvie, Alexander F., ed. 1998. Sophocles: Ajax. Warminster.

Goldhill, Simon. 2012. Sophocles and the Language of Tragedy. New York.

Heritage, John. 2013. Turn-Initial Position and Some of Its Occupants. Journal of Pragmatics 57: 331-37.

Herman, Vimala. 1995. Dramatic Discourse: Dialogue as Interaction in Plays. London.

Holt, Philip. 1981. The Debate-Scenes in the Ajax. AJP 102.3: 275-88.

Jebb, Richard C., ed. 1896. Sophocles: The Plays and Fragments: The Ajax, 2nd ed. Cambridge.

Jong, Irene J. F. de. 1997. Гá $\rho$ Introducing Embedded Narratives. In Rijksbaron 1997b, 175-86.

Judet de la Combe, Pierre, ed. 2001. L'Agamemnon d'Eschyle: commentaire des dialogues. Villeneuve d'Ascq.

Kamerbeek, Jan C., ed. 1963. The Plays of Sophocles: Part I: The Ajax, 2nd ed. Leiden. 
Konishi, Haruo. 1989. Agamemnon's Reasons for Yielding. AJP 110.2: 210-22.

Kovacs, David, ed./trans. 1995. Euripides, vol. 2. Cambridge, Mass.

Kroon, Caroline H. M. 1995. Discourse Particles in Latin: A Study of nam, enim, autem, vero, and at. Amsterdam.

. 2011. Latin Particles and the Grammar of Discourse. In A Companion to the Latin Language, ed. James Clackson, 176-95. Malden, Mass.

Kühner, Raphael, and Bernhard Gerth. 1904. Ausführliche Grammatik der griechischen Sprache, II. Tl.: Satzlehre, II. Bd. Hannover.

Levinson, Stephen C. 1983. Pragmatics. Cambridge.

Liddicoat, Anthony. 2007. An Introduction to Conversation Analysis. London.

Lloyd-Jones, Hugh, ed./trans. 1994. Sophocles. Cambridge, Mass.

Lloyd-Jones, Hugh, and Nigel G. Wilson, eds. 1990. Sophoclis fabulae. Oxford.

Mandala, Susan. 2007. Twentieth-Century Drama Dialogue as Ordinary Talk: Speaking Between the Lines. London.

Mastronarde, Donald J. 1979. Contact and Discontinuity: Some Conventions of Speech and Action on the Greek Tragic Stage. Berkeley, Calif.

Michelini, Ann N. 1987. Euripides and the Tragic Tradition. Madison, Wis.

Minchin, Elizabeth. 2007. Homeric Voices: Discourse, Memory, Gender. Oxford.

Neitzel, Heinz. 1977. Die Stichomythie zwischen Klytaimestra und Agamemnon (Aischylos, ‘Agamemnon' 931-943). RhM 120: 193-208. 
Pfeiffer-Petersen, Sabine. 1996. Konfliktstichomythien bei Sophokles: Funktion und Gestaltung. Wiesbaden.

Pomerantz, Anita, and John Heritage. 2012. Preference. In Sidnell and Stivers 2012, 210-28.

Psathas, George. 1995. Conversation Analysis: The Study of Talk-in-Interaction. Thousand Oaks, Calif.

Raeburn, David A., and Oliver R. H. Thomas, eds. 2011. The Agamemnon of Aeschylus: A Commentary for Students. Oxford.

Revuelta, Antonio R. 2014. Particles (Syntactic Features). In Encyclopedia of Ancient Greek Language and Linguistics, ed. Georgios K. Giannakis. http://referenceworks.brillonline. com/entries/encyclopedia-of-ancient-greek-language-and-linguistics.

Rijksbaron, Albert, ed. 1997a. Introduction. In Rijksbaron 1997b, 1-14. 1997b. New Approaches to Greek Particles. Amsterdam. , ed. 2007. Plato: Ion, or: On the Iliad. Leiden.

Rutherford, Richard B. 2012. Greek Tragic Style: Form, Language and Interpretation. Cambridge.

Sacks, Harvey 1992. Lectures on Conversation, ed. by Gail Jefferson. Oxford.

Sacks, Harvey, Emanuel A. Schegloff, and Gail Jefferson. 1974. A Simplest Systematics for the Organization of Turn-Taking for Conversation. Language 50: 696-735.

Schegloff, Emanuel A. 2007. Sequence Organization in Interaction: A Primer in Conversation Analysis I. Cambridge.

Schuren, Liesbeth. 2014. Shared Storytelling in Euripidean Stichomythia. Leiden. 
Schwyzer, Eduard, and Albert Debrunner. 1950. Griechische Grammatik, II. Bd: Syntax und Syntaktische Stylistik. München.

Sidnell, Jack. 2010. Conversation Analysis: An Introduction. Malden, Mass.

Sidnell, Jack, and Tanya Stivers, eds. 2012. The Handbook of Conversation Analysis. Chichester.

Simpson, Michael. 1971. Why Does Agamemnon Yield? PP 26: 94-101.

Slings, Simon R. 1997. Adversative Relators between PUSH and POP. In Rijksbaron 1997b, 101-30.

Smith, Daniel Lynwood. 2012. The Rhetoric of Interruption: Speech-Making, Turn-Taking, and Rule-Breaking in Luke-Acts and Ancient Greek Narrative. Berlin.

Smyth, Herbert W. 1956. Greek Grammar, rev. by Gordon M. Messing. Cambridge, Mass.

Sommerstein, Alan H., ed./trans. 2008. Aeschylus. Cambridge, Mass.

Stanford, William B., ed. 1963. Sophocles: Ajax. London.

Taplin, Oliver. 1978. Greek Tragedy in Action. Berkeley, Calif.

Toolan, Michael J. 1985. Analysing Fictional Dialogue. Language \& Communication 5.3: 193206.

Wakker, Gerry C. 1997. Emphasis and Affirmation: Some Aspects of $\mu \eta \dot{\nu}$ in Tragedy. In Rijksbaron 1997b, 209-32.

—. 2009. "Well I Will Now Present My Arguments": Discourse Cohesion Marked by oũv and coívvv in Lysias. In Bakker and Wakker 2009, 63-82.

Winnington-Ingram, R. P. 1980. Sophocles: An Interpretation. Cambridge. 
Wooffitt, Robin. 2005. Conversation Analysis and Discourse Analysis: A Comparative and Critical Introduction. Thousand Oaks, Calif.

Worman, Nancy. 2012. Oedipus, Odysseus, and the Failure of Rhetoric. In Brill's Companion to Sophocles, ed. Andreas Markantonatos, 325-48. Leiden.

Wright, Matthew. 2013. Review of Rutherford 2012. CR 63.1: 33-34. 


\section{Notes}

* I wish to thank Felix Budelmann, Albert Rijksbaron, the two anonymous referees for CP, and audiences in Heidelberg and Rome for many helpful comments and suggestions on (versions of) this paper.

${ }^{1}$ As far as I have been able to trace, very few works on (ancient) Greek show any awareness of the tradition, and fewer still use it at length and consistently. Among the latter might be reckoned Smith 2012; Schuren 2014, among the former Minchin 2007; Drummen 2009. CA will receive more attention in van Emde Boas forthcoming, and in Bonifazi, de Kreij, and Drummen forthcoming. Works related in approach, if not explicitly informed by CA, are (e.g.) Mastronarde 1979; Slings 1997; see also n. 6 below. Outside classics, CA has been applied to literature (especially drama) more frequently, particularly in the Stylistics tradition: good examples include Toolan 1985; Herman 1995; Culpeper 2001; Mandala 2007.

${ }^{2}$ The foundational works are Sacks, Schegloff, and Jefferson 1974 and Sacks 1992 (his posthumously published lectures), now supplemented by Schegloff 2007 (whose terminology I use below). Good introductions to the field may be found in Levinson 1983, Liddicoat 2007, Sidnell 2010, and, very fully, in Sidnell and Stivers 2012. A great deal of attention has been paid in CA to discourse markers (particles) such as okay, well, oh, etc.: for an overview cf. Heritage 2013.

${ }^{3}$ Cf. e.g. the index of Sidnell and Stivers 2012, s.v. "languages."

${ }^{4}$ A similar argument is made (more fully) by Schuren 2014, ch. 1, and in the Stylistics works mentioned in n. 1. For the general idea that linguistics does not stop "working" in tragic texts, cf. also (e.g.) Dik 2007, 5-8. 
${ }^{5}$ For detailed comparisons of the two disciplines, cf. Levinson 1983, 286-94, Wooffitt 2005.

${ }^{6}$ Kroon 1995, summarized in 2011. Kroon's work inspired much work on Greek particles, particularly in such collected volumes such as Rijksbaron 1997b; Bakker and Wakker 2009. Its influence may also be felt in Revuelta 2014 (a helpful encyclopedia entry on particles).

${ }^{7}$ There are several other central topics in CA, foremost among which is the turn-taking system itself: the mechanisms and processes by which the floor (the right to speak) is passed from one speaker to the next in a conversation. Overlaps, interruptions and silences are crucial here, and the last two of those are certainly relevant to tragic dialogue as well.

${ }^{8}$ My examples are loosely based on actual conversations recorded in the CA-literature, not precise reproductions: CA has specific set of transcription conventions, which are less relevant for literary dialogue.

${ }^{9}$ There is cultural variation in preference phenomena, so that the patterns identified in fig. 1 cannot be transposed automatically to ancient Greek dialogue. The Greek preference system for blame, in particular, seems worthy of investigation. The preference for denial as a reaction to blame, identified in the table, rests on the empirical observation that denials in English are typically produced in a simpler form (without pauses, hedges or explanations) than admissions, but it is intuitively likely that this pattern does not map simply onto Greek (literary) dialogue. In truth, the English preference system for blame is the subject of considerable debate in the CAliterature (cf. e.g. Pomerantz and Heritage 2012, 226-27).

${ }^{10}$ Giving full bibliography at this point seems, accordingly, a futile exercise. I restrict myself to listing, apart from the major commentaries (Fraenkel 1950; Denniston and Page 1957; Judet de la Combe 2001; Raeburn and Thomas 2011), a selection of discussions which seem especially apposite: Simpson 1971; Easterling 1973; Neitzel 1977; Taplin 1978, 78-82; Konishi 1989. 
${ }^{11}$ Fraenkel 1950, ad 931f.

${ }^{12}$ I am well aware that a schematic analysis of the kind offered here may be seen as at once too precise (in not allowing room for ambiguity and multiple meanings) and too vague (in reducing turns with nuanced communicative functions to items such as "request" or "assessment"). My aim in presenting the passage this way is merely to highlight its basic structural features, not to offer an exhaustive reading.

${ }^{13}$ The text of the stichomythia is not without problems, although Fraenkel's readings (1950, ad locc.) seem to have been almost universally accepted. The text and translation printed here are those of Sommerstein 2008 (spelling adapted, here and in translations below).

${ }^{14}$ Raeburn and Thomas 2011, ad loc. and Fraenkel 1950, ad loc., respectively.

${ }^{15}$ Fraenkel 1950, ad 931f.: he cites Denniston 1954, 352.

${ }^{16}$ Cf. n. 6 above. For a sustained critique of Denniston (a book of immeasurable value, but also the product of a time before advances in linguistics allowed more accurate descriptions of particles), cf. e.g. Rijksbaron 1997a.

${ }^{17}$ Wakker 1997.

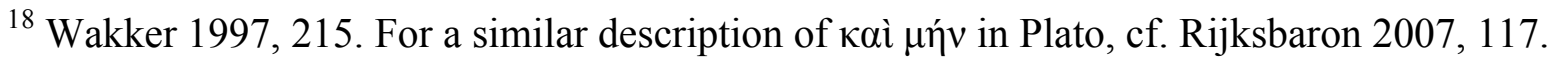

${ }^{19}$ Wakker 1997, 217-18.

${ }^{20}$ Wakker 1997, 214-15 n. 13.

${ }^{21}$ The issue of scope and hierarchical embedding plays a major role in Kroon's discussion of Latin discourse particles (1995, esp. 80-89), and has subsequently also been studied in relation to Greek particles. Noteworthy in this respect are, e.g., Slings 1997 (on "PUSHes" and "POPs"), de

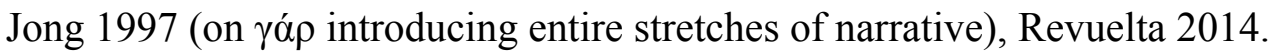

${ }^{22}$ Some other instances are Aesch. Pers. 992, Supp. 311, Hel. 1079, Cyc. 141, 541. 
${ }^{23}$ In such contexts, too, notions of addressee expectation seem to be at work: see van Erp Taalman Kip 2009.

${ }^{24}$ Cf. Denniston 1954, 353-6.

${ }^{25}$ In general, in research on Greek particles, there is insufficient attention for different kinds of contexts in which a particle appears, not only in terms of text types (monologue, dialogue; narrative, argument, etc.) and utterance types (declaratives, interrogatives, etc.), but also, at a more detailed level, the different kinds of points and transitions at which a particle may appear. In this regard, Slings's warning $(1997,126)$ remains salutary: "Only through the painstaking examination of various types of contexts ... can we really advance. Until then, making pronouncements on basic values [of particles] amounts to little more than armchair linguistics."

${ }^{26}$ For $\delta \varepsilon ́$ as a marker of "boundaries," see Bakker 1993.

${ }^{27}$ The use of (enclitic) vov in commands and requests is well treated, however, in (e.g.) Kühner and Gerth 1904, 118-19; Schwyzer and Debrunner 1950, 570-1; Smyth 1956, §2926. More recently, cf. Finglass 2007.

${ }^{28}$ Fraenkel 1950, ad loc.

${ }^{29}$ For vov as an indicator of "coming to the point," cf. Wakker 2009, 72-79 (on vvv in the combination $\tau o$ óvvv).

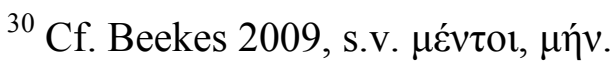

${ }^{31}$ Slings 1997, 114-22.

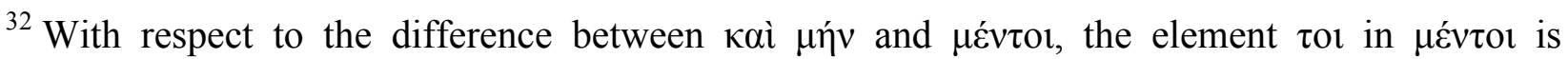
important as well: $\mu \varepsilon ́ v \tau o l$ seems to be more specifically oriented to the addressee and the extent to which the contribution frustrates her/his expectations, whereas kaì $\mu \eta ́ v$ focuses more on the new direction in the discursive line. 
${ }^{33}$ Denniston 1954, 16; Ag. 944 is listed at 17.

${ }^{34}$ Basset 1997; Drummen 2009. Drummen's article is particularly relevant for its focus on "turninitial" $\dot{\alpha} \lambda \lambda \dot{\alpha}$ (i.e. its use as a marker of conversational turns); but also see next $\mathrm{n}$.

${ }^{35}$ This use of $\dot{\alpha} \lambda \lambda \dot{\alpha}$ is very closely paralleled in tragedy and elsewhere, with an identical pattern: a request (FPP) is made by a first speaker; objections are raised by the second speaker (insertexpansions); when the objections do not yield the desired change of approach from the first speaker, the second speaker gives up ( $\dot{\alpha} \lambda \lambda \dot{\alpha})$ and consents to the original request. Some examples are Soph. Aj. 1370 (discussed below), Phil. 645 (Neoptolemus agrees to leave, after his delaying tactics are forestalled); Eur. El. 1132 (Clytemnestra agrees to go into the house even though she is unimpressed by Electra's answers to her objections; Weil's transposition of 1107-8 should be ignored, cf. Michelini 1987, 222 n. 179, Mastronarde 1979, 91-92); Ar. Ach. 409 (an à $\lambda \lambda \dot{\alpha}-$ rich passage). Such examples are, I suggest, different from those where $\dot{\alpha} \lambda \lambda \dot{\alpha}$ follows immediately upon the request (in which case it corrects the implication of possible dissent rather than replacing the preceding conversational moves in which dissent has actually been offered): Drummen $(2009,149$ n. 32) lists Aesch. $A g .944$ under the wrong header.

${ }^{36}$ Denniston and Page 1957, ad $931 \mathrm{ff}$.

${ }^{37}$ Raeburn and Thomas 2011, ad 944-9.

${ }^{38}$ Again, a full bibliography on the scene is not feasible. Apart from commentaries (Jebb 1896; Kamerbeek 1963; Stanford 1963; Garvie 1998; Finglass 2011), I have found the following particularly useful: Winnington-Ingram 1980, 67-69; Holt 1981, 286-88; Pfeiffer-Petersen 1996, 30-35; Worman 2012, 342-44. 
${ }^{39}$ Stanford comes closest in his note on 1353 (1963). Ajax has no secure date, but is normally dated after the Oresteia: for an overview of the debate, cf. Finglass 2011, 1-11. For Ajax as an “Aeschylean” play, cf. Davidson 2012, 48-49.

40 This parallel has been observed often, although the commentaries do not mention

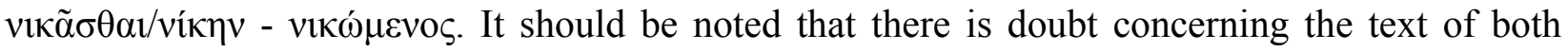
lines (cf. Fraenkel 1950, ad loc.; Denniston \& Page 1954, ad loc.; Finglass 2011, ad loc.), and

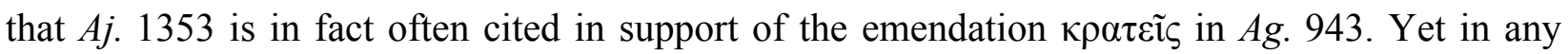
case the parallel runs deeper than verbal similarities: both Clytemnestra and Odysseus intervene when Agamemnon makes things personal and tries to exploit power relationships between himself and Clytemnestra/Odysseus (man vs. woman, king vs. subject).

${ }^{41}$ Text: Lloyd-Jones and Wilson 1990. Translation: Lloyd-Jones 1994.

${ }^{42}$ Here and at 1364, Agamemnon's questions resemble the repair-initiators described above: Agamemnon wants to know whether he has heard/interpreted Odysseus correctly: of course, such repair-initiators are often suggestive of dissent (in CA-terms, they can function as pre-rejections). ${ }^{43}$ According to Pfeiffer-Petersen (1996, 30), 1350 marks a new stage of the conversation: 'in 1350 weicht [Agamemnon] auf einen anderen Aspekt des Geschehens aus — Sophokles läßt Odysseus' Kritik an Agamemnons zweiter Frage [1349] damit als abschließendes Urteil

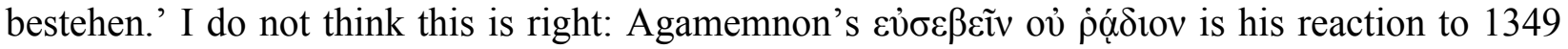
(the idea is: "living by your rule is not so simple"), so that that line can hardly be taken as "abschließend." The particle $\tau$ or in Agamemnon's reply supports this: it is a sign for Odysseus to derive particular relevance from Agememnon's objection, precisely because 1350 has bearing on Odysseus' advice.

${ }^{44}$ It is not easy to capture the role 1352 plays in the sequence: cf. $n$. 64 below. 
${ }^{45}$ A way of looking at this in terms of tragic conventions is that, whereas in Agamemnon the stichomythia follows on multiple longer rheseis (Clytemnestra 855-913 and Agamemnon 91430, FPP and SPP), in Ajax the stichomythia follows on only one (Odysseus 1332-45, FPP), with the answer to Odysseus' request left hanging in the stichomythic balance.

46 “ $[\mathrm{H}] \mathrm{e}$ is no fawning wheedler in this scene, but a determined man prepared to be polite, respectful and patient with the man in supreme authority" (Stanford 1963, ad 1360-61). At two moments, 1349 and 1353, Odysseus seems more forceful (these are his only two FPPs of the stichomythia): in fact his strategy appears to shift slightly after the initial exchanges, once he has got Agamemnon to retreat from his power play of 1352 .

${ }^{47}$ Pfeiffer-Petersen 1996, 30-32. Cf. also Finglass 2011, ad 1316-73.

${ }^{48}$ Mid-turn particles such as $\dot{\alpha} \lambda \lambda \alpha \dot{~ i n ~} 1355$ are obviously less relevant for an analysis in terms of conversational structure. In Greek, a language whose discourse markers are often postpositives, "turn-initial" should of course not be taken to refer strictly to the first word of a turn.

${ }^{49}$ Goldhill 2012, 58. Goldhill's discussion of the Antigone-passage is at pp. 58-62.

${ }^{50}$ Cf. the discussion of Latin nam in Kroon 1995; on yóp cf. also de Jong 1997.

${ }^{51}$ From the Antigone-examples discussed by Goldhill, 736 is perhaps parallel to this case, even if Haemon's response at 737 (again with $\gamma \alpha \dot{\rho} \rho$ ) answers Creon's rhetorical question as if it were a real one (i.e. treats it like a FPP rather than a SPP).

${ }^{52} \gamma$ ó $\rho$ cannot be used to answer (non-rhetorical) specifying ("wh-") questions, for reasons which will become clear.

${ }^{53}$ From Goldhill's examples, cf. Ant. 737, 743, 745. 


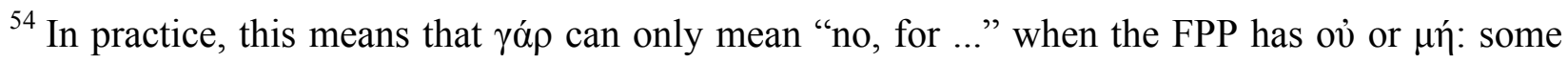
examples in tragedy are Aesch. Cho. 173-74, Soph. Aj. 1121, Eur. Alc. 814-15, Hec. 1268-69, Or. 794-95.

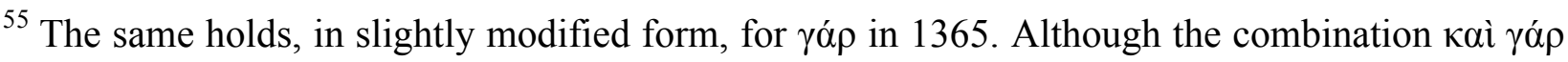
is often to be analyzed as a unit (typically translated "(and) in fact"), in other cases the particles appear to function separately. This is the case here, with kai functioning as a "scope particle"

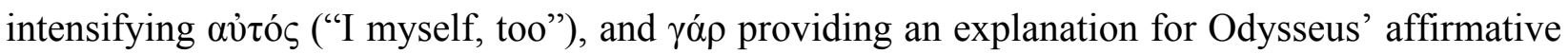
answer "̌ $\gamma \omega \gamma \varepsilon$. This use of $\gamma \alpha \dot{\alpha} \rho$ is thus similar to Odysseus' other uses in the passage, except that the answer "yes" is provided separately $(\stackrel{\varepsilon}{\gamma} \gamma \omega \gamma \varepsilon)$.

${ }^{56}$ Several of the cases that Goldhill discusses from the Antigone open insert-expansions: 730, 734, 744, and possibly also 736 (cf. n. 51 above).

${ }^{57} \gamma \alpha \dot{\rho} \rho$ in such contexts may even be translated "then" or "so," which ought, however, not to be taken to mean that it can express inference or consequence.

${ }^{58}$ In the Antigone-passage that Goldhill discusses, too, it is only the speaker taking the role of aggressive questioner (Creon) who uses yó $\rho$ to initiate insert-expansions.

${ }^{59}$ Denniston 1954, 76-80.

${ }^{60}$ Denniston 1954, 81-85.

${ }^{61}$ Denniston 1954, 82, 81.

${ }^{62}$ Finglass 2011, ad loc.

${ }^{63}$ Cf. Finglass 2011, ad loc.: " $\alpha \lambda \lambda \dot{\alpha}$ has the nuance 'well, if you persist in your foolish behaviour'." 


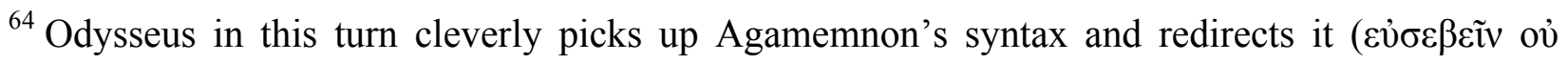

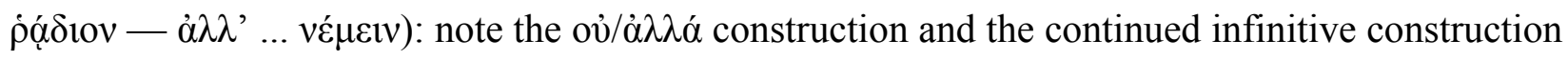

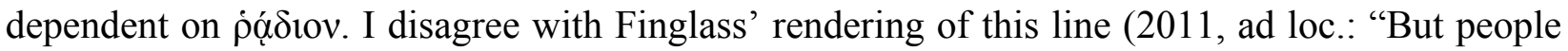

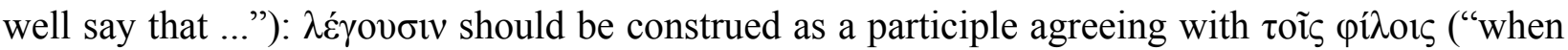
they give good advice"). As for the sequencing of these two turns and the next (1350-52): the accumulation of closely parallel statements (note the three infinitives depending on impersonal constructions) seems to suggest a form of continuity. Yet 1352 is in some ways a disruption of the sequence, in that Agamemnon does not really engage with Odysseus' remark (which is about what he as king should do) but rather baldly asserts his authority, talking about what Odysseus as subject should do. In CA-terms, this perhaps comes closer to a counter (a new FPP is posited in place of the ongoing sequence) than to a post-expansion (a FPP reopens the preceding sequence). Agamemnon's power play in turn elicits Odysseus' interruption $\pi \alpha \tilde{v} \sigma \alpha 1$ at 1353: cf. n. 40 above. ${ }^{65}$ Denniston 1954, 400, followed by Finglass 2011, ad loc. Incidentally, that the "emphatic" use

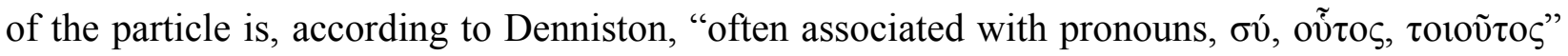
$(1954,399)$ does not prevent him from classifying many instances with such demonstratives under different headers: contrast particularly his examples at p. 405 (under 2.iii) and pp. 407-9 (under 3.ii).

${ }^{66}$ For the term, cf. Finglass 2011, ad loc. Agamemnon's intended referent is clearly Ajax, not Odysseus, as Finglass well argues.

${ }^{67}$ Goldhill's book referenced above is self-reflexively so $(2012,3)$; another good example is Rutherford 2012: see Wright's review (2013).

${ }^{68}$ Cf. e.g. Schuren 2014 on "narrative" stichomythia-passages. The application of CA to Platonic dialogue holds particular promise. 